\title{
COMPARISON OF DIFFERENT ALTERNATIVE TYPES OF OSTEOSYNTHESIS FOR MANAGEMENT OF PEDIATRIC MANDIBULAR FRACTURES
}

\author{
Khaled A. Saad*
}

\begin{abstract}
This study was planned to evaluate both clinically and radiographically different plating systems for treatment of pediatric mandibular fractures.

Patients and Methods: 36 children with mandibular fractures at different sites, their ages in between 5-12 years with a mean of age 8.5 years. All patients treated via an intraoral approach with open reduction and internal fixation, using miniplates, microplates, biodegradable plates. All patients were examined clinically by inspection and palpation both extra orally and intra orally. Radiographically by orthopantomograms. All patients were evaluated both clinically and radiographically immediately, at one week, two weeks, at one month, three and six months postoperatively.
\end{abstract}

Results: the results of this study revealed primary wound healing was achieved uneventfully in 32 patients with no signs of infection. Proper occlusion without any discrepancy postoperatively, except only minor occlusal derangement in only two cases of group (3) corrected by placement of light guiding elastics. Radiographic examination revealed significant bone healing at the fracture line, nonunion didn't occur in any patient of our study.

Conclusion: Monomandibular osteosynthesis using miniplates, microplates, and biodegradable plates precludes dependence on the maxillomandibular fixation, ensure respiratory care, nutritional intake in children, provided adequate stability of the fracture segments, minimize the possibility of trauma to the teeth buds. In addition the biodegradable plates characterized by no need for removal of the plates later on.

\section{INTRODUCTION}

Mandibular fractures are the most common facial injuries seen in children. Children with mandibular fractures always have unique fractures such as changing age incidence, size of the jaw, different dentation phases, and more elastic bone, presence of teeth buds and the possibility of growth disturbances. ${ }^{1}$

* Ass. Professor, Oral and Maxillofacial Surgery Dept., Faculty of Dentistry, Tanta University. 
When formulating a plan of treatment for pediatrics with facial trauma, a number of elements must be considered. These include the age of the patient (to maximize growth and development), the anatomical site (to optimize form and function), the complexity of the injury (displacement, comminution) and the number of sites, concomitant injury (fitness for anaesthesia and duration of surgery) and the surgical approach (closed versus open). ${ }^{2}$

There are several ways by which pediatric mandibular fractures could be treated. Fracture immobilization when required can be achieved by maxillomandibular fixation, simple methods such as arch bar and dental wires are associated with some problems such as instability, rotation and displacement of fracture segments. The shape of primary dentition and the degree of root resorption often limits their utility as retentive abutments. ${ }^{3}$

Monomandibular acrylic splints, or internal skeletal fixation or combination of these frequently used, depending up on the type of fracture and patient's age and tooth development. ${ }^{4}$

Contemporary surgical repair relies heavily on open reduction and internal fixation, consequently multidisciplinary approaches are followed for management of pediatric mandibular fractures in children, however can be complicated by a mixed dentition that can occupy the entire vertical dimension of the bone and places the teeth and the inferior alveolar nerve at risk during screw insertion, in addition, ongoing development of the mandible poses risk of intrabony translocation of metal plates and screws, risking potential growth and teeth disturbances, difficulty with secondary removal if needed. Compatibility with future imaging needs long term palpation and thermal sensitivity. For these reasons the use of resorbable fixation implants in developing facial bones is particularly appealing 6 ,7,8.

Biodegradable plates and screws are used increasingly in oral and maxillofacial practice, these biodegradable plates and screws have several advantages over conventional titanium including: no need for a second intervention to remove the device, no possible growth disturbances and no thermal sensitivity. ${ }^{9}$

Closed and open reduction of fractures of the mandible constitutes endless debates and modern times have not brought a conclusion to this controversy. This study aimed to evaluate both clinically and radiographically different plating systems for treatment of pediatric mandibular fractures.

\section{PATIENTS AND METHODS}

This study was conducted on 36 children with mandibular fractures. Patients attended to the outpatient clinic of Oral and Maxillofacial Surgery Department. Faculty of Dentistry, Tanta University. Patient's age ranged between 5-12 years with a mean of age 6.5 years. Twenty eight patients were males while eight patients were females.

All patients were examined for clinical features as: swelling, pain, hematoma, crepitation, displacement and mobility of teeth, derangement of occlusion, limited mouth opening and sensory deficits with the distribution of the inferior alveolar nerve. Other concomitant injuries elsewhere in the body were thoroughly examined.

The demographic data of the patients were recorded from the patients themselves, their parents or relatives including personal data (name, age, sex, address and telephone number), time of injury, past medical and dental history, and associated injuries.

Radiographic examination was done by the use of panoramic views, these were supplemented by postero anterior views, lateral oblique views, CT scan indicated in cases of condylar fractures.

Patients were divided into three equal groups according to the method of osteosynthesis as the following: 
- Group (1): comprised (12) patients with displaced mandibular fractures treated by open reduction and internal fixation using monocortical non compression miniplates/ screws system.

- Group (2): comprised (12) patients with displaced mandibular fractures treated by open reduction and internal fixation using microplates/ screws system.

- Group (3): comprised (12) patients with displaced mandibular fractures treated using biodegradable resorbable bone plates/screws systems.

All patients were treated by open reduction and internal fixation under general anaesthesia, via nasoendotracheal intubation, before starting the surgical procedures prophylactic antibiotics and analgesic and anti-inflammatories were given the day before surgery every $12 \mathrm{hs}$ and continued postoperatively for one week. Preliminary intermaxillary fixation was done and proper occlusion was achieved.

All patients were treated through an intraoral approach via vestibular incision, anatomical reduction of all fractures was achieved manually, then the plates either miniplates, microplates or resorbable plates according to the three groups fixed accurately in their position, and then the incision properly approximated and sutured with Vicryl 3/0.

All patients were carefully observed during recovery from general anaesthesia with special attention to respiration, pulse and blood pressure. The prophylactic antibiotics and analgesics were continued for one week postoperatively for all patients.

All patients were instructed to take fluids and semisolid diets for the $1^{\text {st }}$ three weeks.

All patients were followed up immediately, at two weeks, and at one, three and six months postoperatively as following:-
The patients were evaluated clinically immediately regarding to the occlusion and stability of the reduced segments.

After two weeks the wound was inspected for wound dehiscence, infection. Occlusion was inspected by estimation of the midline anteriorly and intercuspation posteriorly to detect any occlusal discrepancy.

At one, three and six months, union of the fracture is tested for mobility at the fracture site bimanually.

Panoramic radiographs were done to detect the accuracy of bone healing and proper approximation, at the fracture site immediately and at one, three and six months postoperatively.

The panoramic radiographs were digitally analyzed using the "Quantitative Digital Radiography" and "Gray level detector program" according to Chen \& Hollendar $1995^{10}$, the collected data was organized and tabulated and statistically analysed using "SPSS" software statistical computer package version 18 for quantitative data, the range, mean and standard deviation were calculated for comparison of mean values at different periods of follow up. Significance was adopted at $(p<0.05)$ for interpretation of the results of the tests of significance.

\section{RESULTS}

This study was conducted on 36 patients (28 males and 8 females) suffering from displaced mandibular fractures treated with open reduction and internal fixation via three different types of osteosynthesis. All patients were followed up for six months postoperatively both clinically and radiographically.

Primary wound healing uneventfully was achieved in four patients with no signs of infection. All patients had good alignment and proper occlusion without any discrepancy postoperatively except three patients had minor occlusal discrepancies postoperatively corrected by guiding elastics for 10 days. 
The stability for fracture segments was achieved in all cases as healing of bone examined clinically at one, three and six months as the fracture is tested for mobility at the fracture site bimanually.

TABLE (1) Percentage of etiology of 36 pediatric mandibular fractures

\begin{tabular}{|c|c|c|}
\hline Causes & No. & $\%$ \\
\hline Traffic accident & 9 & $27.5 \%$ \\
\hline Falling down & 7 & $18.4 \%$ \\
\hline Animal blow & 3 & $9.6 \%$ \\
\hline Sport accident & 15 & $39 \%$ \\
\hline Gymnastic accident & 2 & $5.5 \%$ \\
\hline Total & 36 & $100 \%$ \\
\hline
\end{tabular}

TABLE (2) Incidence of fracture site in the three groups

\begin{tabular}{|c|c|c|c|}
\hline Fracture site & $\begin{array}{c}\text { Group (1) } \\
(\mathrm{n}=12)\end{array}$ & $\begin{array}{c}\text { Group (2) } \\
(\mathrm{n}=12)\end{array}$ & $\begin{array}{c}\text { Group (3) } \\
(\mathrm{n}=12)\end{array}$ \\
\hline Symphysis & 3 & 2 & 3 \\
\hline Parasymphysis & 3 & 2 & 2 \\
\hline Rt body & 2 & 3 & 1 \\
\hline Lt body & 2 & 1 & 3 \\
\hline Rt angle & 1 & 2 & 2 \\
\hline Lt angle & 1 & 2 & 1 \\
\hline Total (n=36) & 12 & 12 & 12 \\
\hline
\end{tabular}

After the dropouts, 36 patients were enrolled in the three groups. Males commonly suspected to trauma more than females, as 28 (77.8\%) patients were males and $8(22.2 \%)$ were females. Demographic variables are summarized in table (1\&2). Symphyseal, parasymphysis and body of the mandible were the most common fracture sites and sports and road traffic accidents were the most common causes of injury. Causes of the fractures and fracture site in each group are summarized in table (1\&2). The mean duration from trauma to admission involving the three groups was 38.2 hours with range of (67 minutes to 149 hours).
Mean duration of procedures for group 1 was 43 minutes, for group 2 was 39 minutes and for group 3 was 45 minutes. There was no case of wound dehiscence in either group. All patients in the three groups had satisfactory postoperative occlusion, two cases of mild segmental mobility in both groups $2,3(\mathrm{p}=0.09)$ and no case of group (1), and two cases of surgical site infection $(\mathrm{p}=0.09)$ were noted in group 2 and 2 cases in group 3 and no cases in group 1 , segmental mobility and infection in group 2,3 were noted during the $1^{\text {st }}$ week of follow up, these conditions were treated by draining of pus, wound debridment, antibiotics and ant-inflammatories for 5 days, and placing maxillo mandibular fixation for 3 weeks, after intervention in these cases of infection, none of the patients required plate removal or any further intervention up to the 2 months follow-up. None of the patients had any signs or symptoms of nerve injury or any other significant postoperative complications. Radiological evaluation didn't show any statistically significant difference between the three groups $(\mathrm{p}=0.07)$. (Table 3$)$

Immediate postoperative radiographs showed accurate reduction and excellent alignment of the fracture segments in all cases. Radiographic examination after one month postopertively revealed no change of the position of the reduced segments in all cases. After three months, the radiographic examination revealed that the fracture line difficult to be detected. It was almost disappeared after six months.

All over the follow up periods, no abnormal reaction, no rarefaction or sequestration in bone seen in all cases. By the end of the follow up period, none of the patients showed any signs of nonunion.

The scale of radioopacity ranged from 0 of black to 255 for the maximum radio opacity (white) and so reflectively the degree of calcification denoted by the amount of bone tissue present (bone density) therefore it gives an idea about the density of the bone in the fracture site in relation to the normal surrounding bone during different follow-up periods. 
TABLE (3) Comparison of clinical and radiographical parameters between the three groups

\begin{tabular}{|c|c|c|c|c|}
\hline Clinical and radiographic parameters & $\begin{array}{c}\text { Group (1) (n=12) } \\
\text { No. of patients } \\
\text { parameters (\%) }\end{array}$ & $\begin{array}{c}\text { Group (2) (n=12) } \\
\text { No. of patients } \\
\text { parameters (\%) }\end{array}$ & $\begin{array}{c}\text { Group (3) (n=12) } \\
\text { No. of patients } \\
\text { parameters (\%) }\end{array}$ & $\begin{array}{c}\text { P. value } \\
\text { t. test }\end{array}$ \\
\hline Duration of operation (mean minutes) & 43 & 39 & - & - \\
\hline Wound dehiscence & - & $2(16.2 \%)$ & $2(16.2 \%)$ & 0.09 \\
\hline Infection & 0 & $2(16.2 \%)$ & $2(16.2 \%)$ & 0.09 \\
\hline Segmental mobility & 0 & - & - & - \\
\hline Improper occlusion & - & $2(16.2 \%)$ & $2(16.2 \%)$ & - \\
\hline Postoperative complication & - & $2(16.2 \%)$ & - & 0.07 \\
\hline Radiogrphical reduction (not \\
satisfactory)
\end{tabular}

The changes in the gray level detection in all cases at different follow-up periods. The mean differences from baseline (immediate postoperative) to the other follow-up periods (after one, three, six months postoperatively) of all patients were statistically analyzed.

The results that the mean gray level of bone gain in the three groups was statistically significant when compared with each other at the end of follow up period at six months.

In group (1), bone gain preoperatively and at different periods of follow up was shown in table (4), fig. (1), the mean value of bone gain preoperatively was found to be $75.82 \pm 2.43$ which showed slight increase immediately after operation to reach $79.35 \pm 3.36$ this increase was not statistically significant $(\mathrm{p}=0.658)$. At one month postoperatively a statistically significant increase in bone gain to reach to $82.37 \pm 3.28$ ( $\mathrm{p}=0.001)$. The bone gain continued to increase at three and six months postoperatively to reach $102.07 \pm 9.51$ and 146.11 \pm 9.79 respectively. These changes were found also stability significant $(\mathrm{p}=0.001)$.

TABLE (4) Comparison of bone gain at different follow up periods in group (1)

\begin{tabular}{|c|c|c|c|c|c|c|}
\hline \multirow{2}{*}{ Follow up periods } & \multicolumn{2}{|c|}{ Gray scale measurements } & \multicolumn{2}{|c|}{ Difference } & \multirow{2}{*}{$\mathrm{t}$. } & \multirow{2}{*}{ P. value } \\
\hline & Range & Mean $\pm \mathrm{SD}$ & Mean & SD & & \\
\hline Preoperatively & $74-80$ & $75.82 \pm 2.43$ & & & & \\
\hline Immediate postoperative & $75-84$ & $79.15 \pm 3.36$ & & & & \\
\hline After 1 month postoperative & $92-97$ & $82.37 \pm 3.28$ & -19.753 & -4.361 & 17.67 & $<0.001 *$ \\
\hline After 3 month postoperative & $118-125$ & $102.07 \pm 9.51$ & -39.521 & -2.932 & -33.89 & $<0.001 *$ \\
\hline After 6 month postoperative & $130-146$ & $136.11 \pm 9.79$ & -52.63 & 2.998 & -35.626 & $<0.001 *$ \\
\hline
\end{tabular}




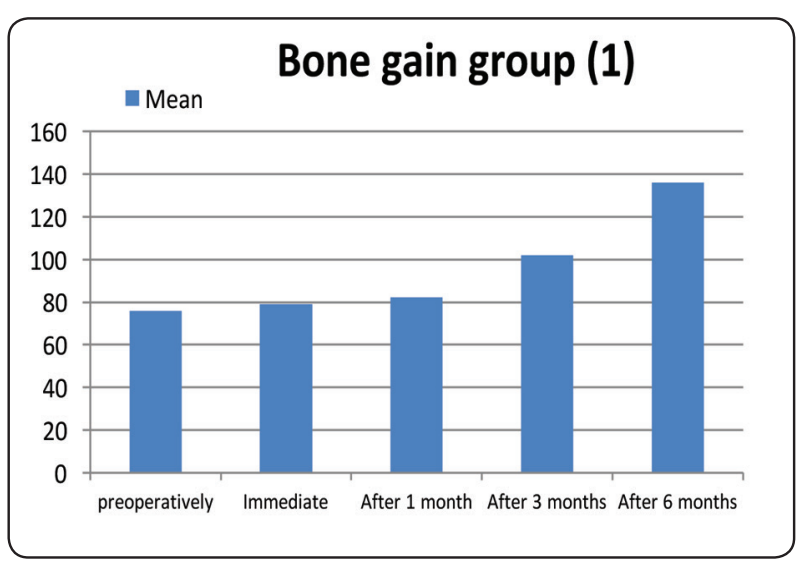

Fig. (1) Showing comparison of bone gain at different follow up periods in group (1)
In group 2, bone gain level preoperatively and at different periods of follow up was shown in table (5), and fig (2). The preoperative mean value of bone gain was $77.15 \pm 4.29$ which showed slight increase immediately after operation to reach 78.05 , however this increase was not statistically significant $(\mathrm{p}=0.558)$. At one month postoperatively a statistically significant increase in bone gain was observed to reach to a mean value of $84.34 \pm 6.23$ $(\mathrm{p}=0.007)$. This significant increase continue at three months to reach to a mean value of $109.07 \pm 9.79$ and up to $133.64 \pm 6.33$ at six months post operatively $(\mathrm{p}=0.001)$.

TABLE (5) Comparison of bone gain at different follow up periods in group (2)

\begin{tabular}{|c|c|c|c|c|c|c|}
\hline \multirow{2}{*}{ Follow up periods } & \multicolumn{2}{|c|}{ Gray scale measurements } & \multicolumn{2}{|c|}{ Difference } & \multirow{2}{*}{ t. } & \multirow{2}{*}{ P. value } \\
\cline { 2 - 5 } & Range & Mean \pm SD & Mean & SD & & \\
\hline Preoperatively & $74-80$ & $77.15 \pm 4.29$ & & & & \\
\hline Immediate postoperative & $75-84$ & 78.05 & & & & \\
\hline After 1 month postoperative & $89-105$ & $84.34 \pm 6.23$ & -5.76 & -18.86 & 17.67 & $<0.001^{*}$ \\
\hline After 3 month postoperative & $117-125$ & $104.78 \pm 9.65$ & -3.872 & -34.97 & -33.89 & $<0.001 *$ \\
\hline After 6 month postoperative & $133-147$ & $139.13 \pm 9.95$ & -51.74 & -35.82 & -35.626 & $<0.001^{*}$ \\
\hline
\end{tabular}

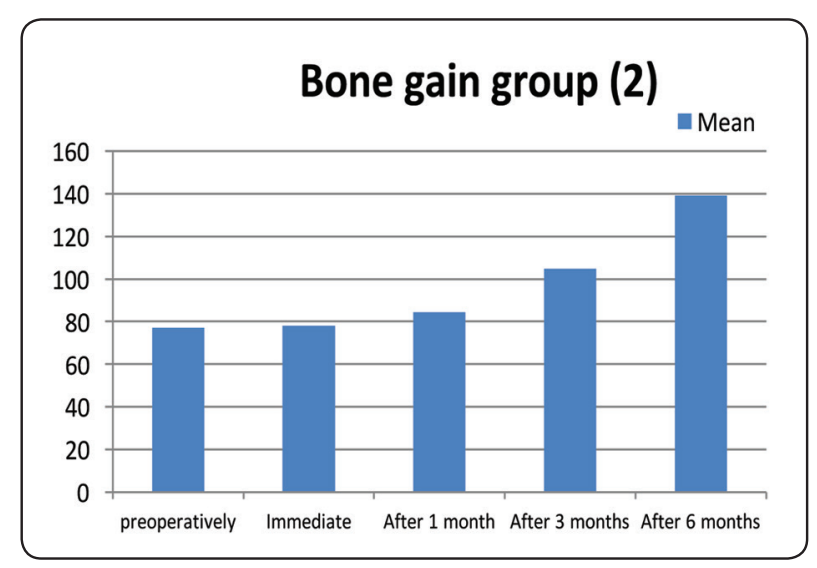

Fig. (2) Showing comparison of bone gain at different follow up periods in group (2)
In group (3) bone gain at different periods of follow-up shown in table (6) and fig (3). The mean value of bone gain preoperatively was $78.07 \pm 4.78$, immediately after operation the mean value slightly increased to $81.87 \pm 3.17$. Increased bone gain was observed at one month to be $94.76 \pm 3.89$ which was significantly higher than the preoperative value $(\mathrm{p}=0.001)$. The increase in bone gain continued at three and six months postoperatively to reach to $112 \pm 3.65$ and $137.15 \pm 4.26(p=0.001)$. These changes were found to be statistically significant. 
TABLE (6) Comparison of bone gain at different follow up periods in group (3)

\begin{tabular}{|c|c|c|c|c|c|c|}
\hline \multirow{2}{*}{ Follow up periods } & \multicolumn{2}{|c|}{ Gray scale measurements } & \multicolumn{2}{|c|}{ Difference } & \multirow{2}{*}{ t. } & \multirow{2}{*}{ P. value } \\
\cline { 2 - 7 } & Range & Mean \pm SD & Mean & SD & & \\
\hline Preoperatively & $72-82$ & $78.07 \pm 4.78$ & & & & \\
\hline Immediate postoperative & $75-85$ & $81.87 \pm 3.17$ & & & & \\
\hline After 1 month postoperative & $88-98$ & $94.763 .89 \pm$ & -21.864 & -6.82 & -18.76 & $<0.001^{*}$ \\
\hline After 3 month postoperative & $120-126$ & $1123.65 \pm$ & -40.343 & -4.987 & -20.67 & $<0.001^{*}$ \\
\hline After 6 month postoperative & $133-148$ & $137.154 .26 \pm$ & -43.545 & -2.786 & -24.76 & $<0.001^{*}$ \\
\hline
\end{tabular}

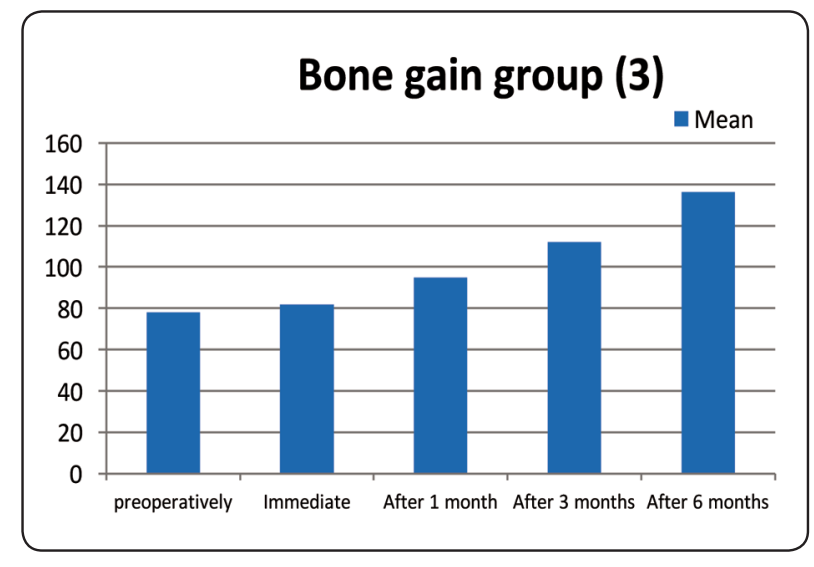

Fig. (3) Showing comparison of bone gain at different follow up periods in group (3)

Comparison of bone gain level between the three groups. At preoperative period there was no significant differences between the three groups ( $p=0.218)$ where the mean value of bone gain in group (1) was $79.35 \pm 3.36$, in group (2) was $77.15 \pm 4.29$ and for group (3) was $78.07 \pm 4.78$.

Immediately after operation the mean value for group (1) was $82.37 \pm 3.28$ and that for group (2) was $78.05 \pm 3.87$ and for group (3) was $81.87 \pm 3.17$, the differences between the three groups were statistically significant $(\mathrm{p}=0.008)$.

The significant difference continue to be observed at different periods of follow-up, after one month, the bone gain mean value for group (1), was
$82.37 \pm 3.98$, for group (2) $84.34 \pm 6.23$ and for group (3), $94.76 \pm 3.89 .(\mathrm{p}=0.002)$

Further increase in bone gain was observed for group (1), at three months postoperatively to reach $102.07 \pm 9.51$ for group (2), was $109.07 \pm 9.79$ and for group (3) was $112.5 \pm 3.65$ and at six months, the bone gain significantly increased for group (1) was $146.11 \pm 9.79$, for group (2) was $133.6 \pm 6.33$ and for group (3) was $137.15 \pm 4.26(\mathrm{p}=0.003)$, these comparison between the three groups determine their great increase bone gain from the immediate postoperative period to the end of the follow up period at six months, and appear to be statistically significant when compared to each other at the different follow up periods.

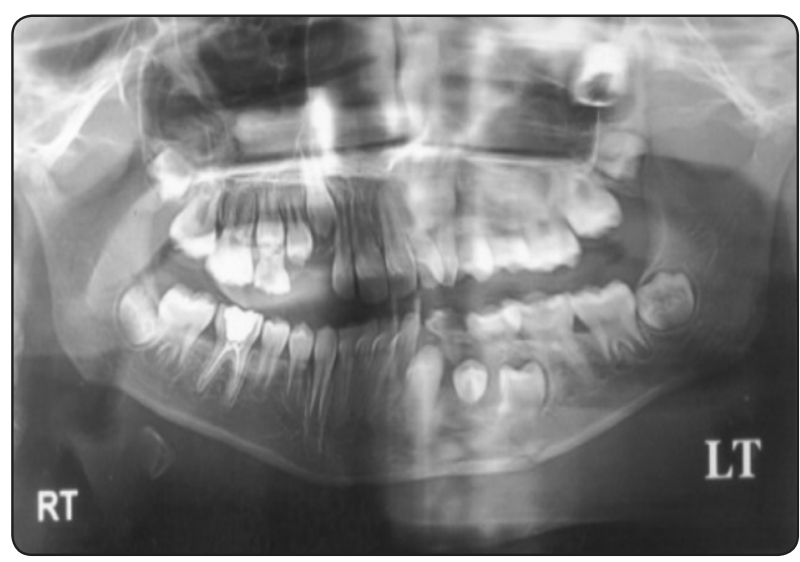

Fig. (4) Ortho pantomograph showing left parasymphsial fracture $(\mathrm{G} 1)$. 


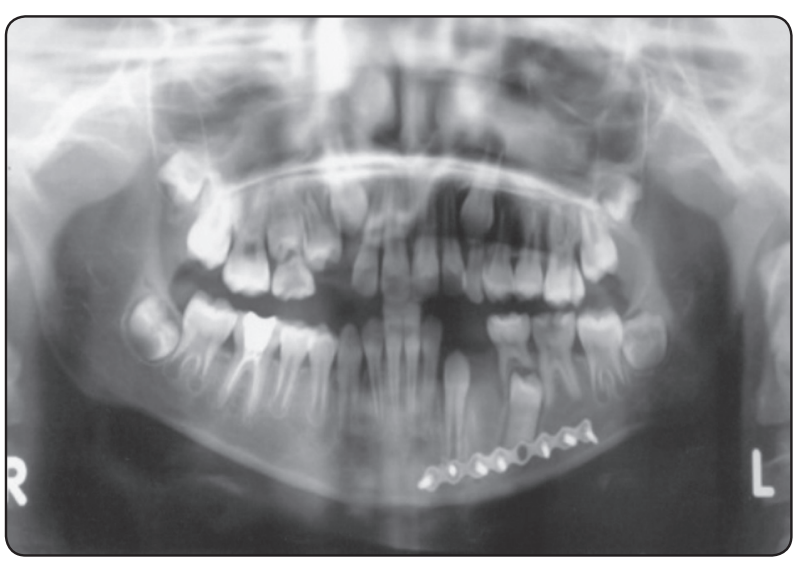

Fig. (5) Ortho pantomograph showing proper reduction and proper fixation of left parasymphsial fracture using miniplate (G 1)

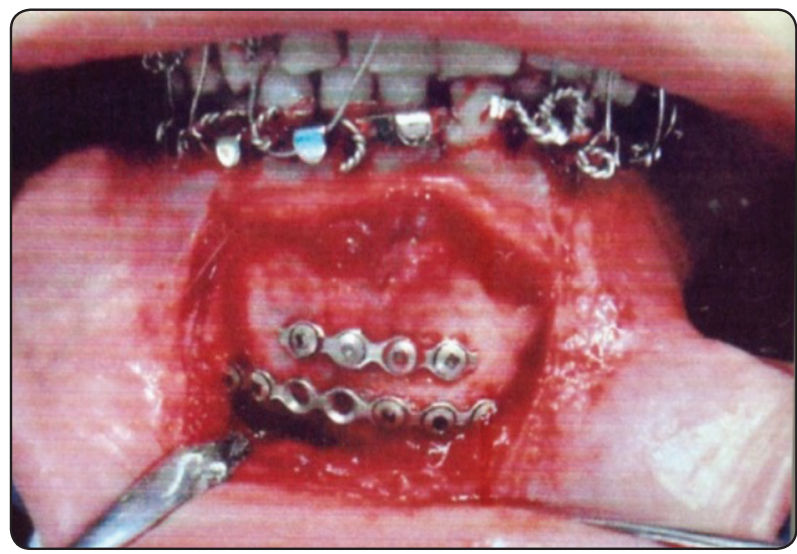

Fig. (7) Intraoperative photograph showing proper reduction of the parasymphsial fracture and proper fixation using two microplates (G2).

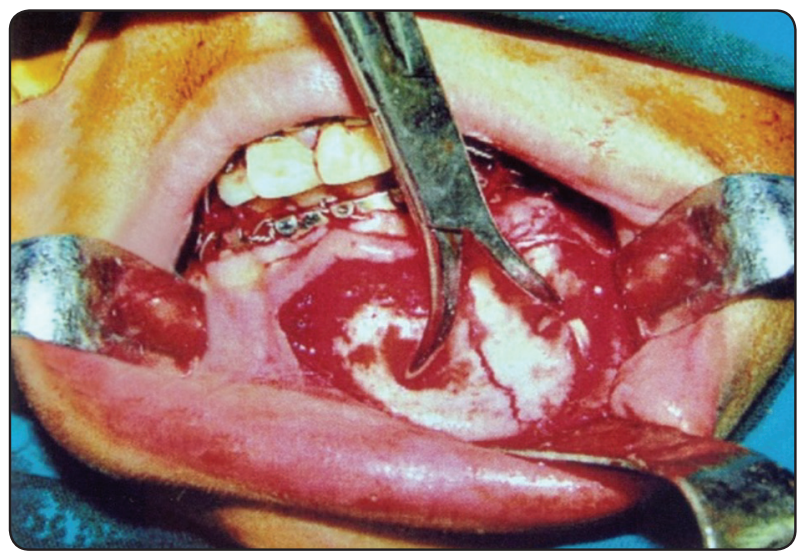

Fig. (9) Intraoperative photograph showing proper approximation of the fracture segments $(\mathrm{G} 3)$.

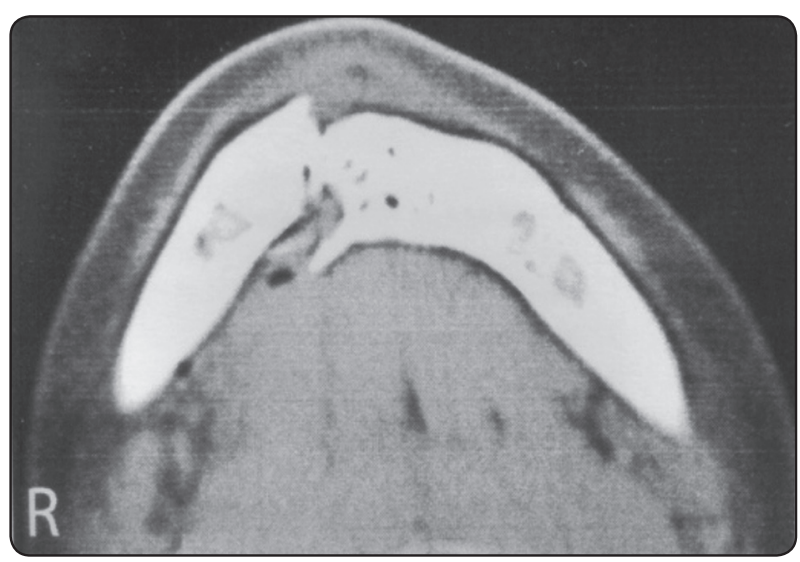

Fig. (6) Axial C.T. scan showing right parasymphsial fracture. (G2).

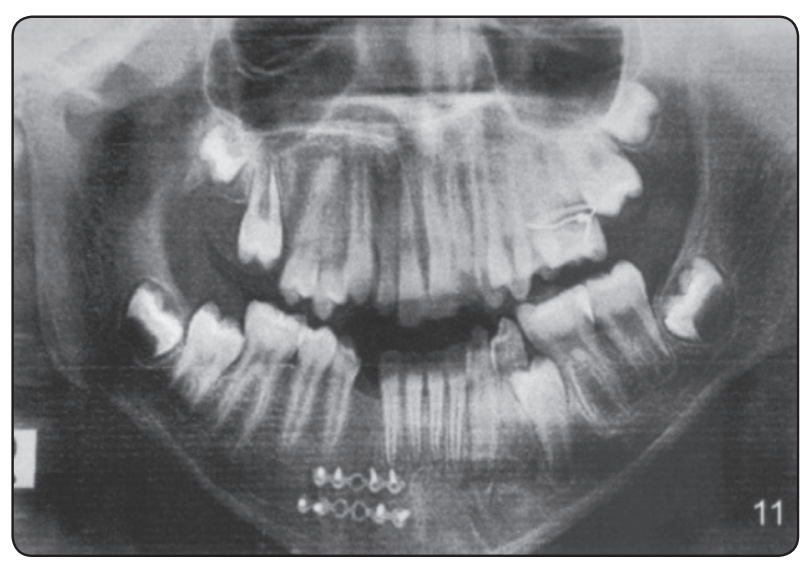

Fig. (8) Orthopantomograph showing proper reduction and fixation of right parasymphsial using microplates (six months postoperative) (G2)

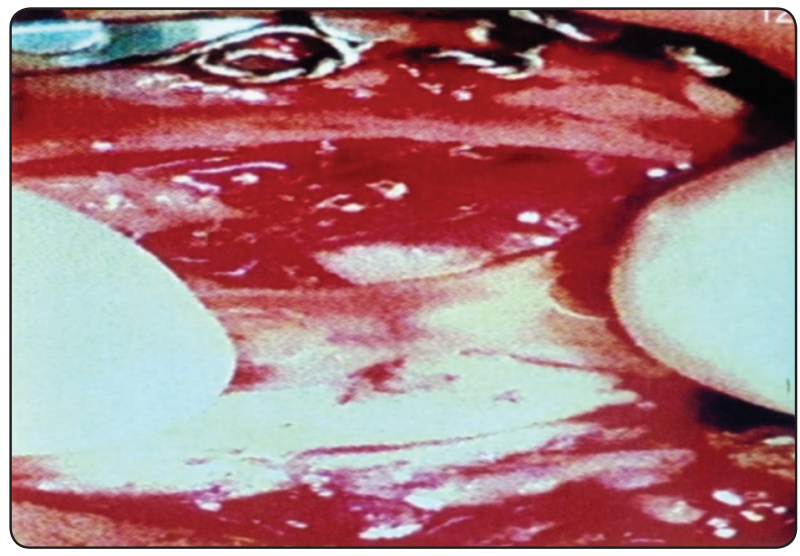

Fig. (10) Intraoperative photograph showing application of biodegradable bone plates for parasymphsial fracture fixation (G3). 


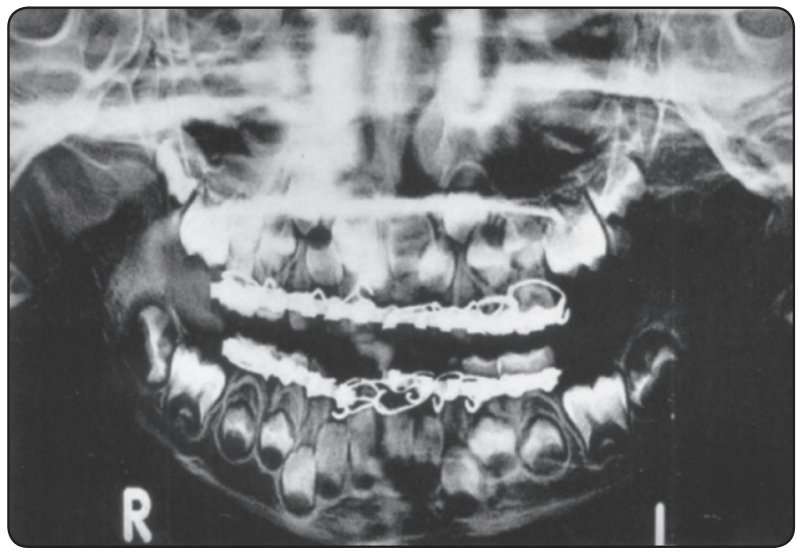

Fig. (11) Orthopantomograph showing accurate reduction and fixation using biodegradble bone plate (one month postoperative) (G3)

\section{DISCUSSION}

Facial fractures in children occur less frequently than in adults, and they are more often minimally displaced, this is because of a thicker layer of adipose tissue covers the more elastic bones and the suture lines are flexible, in addition, stability is increased by the presence of teeth buds within the jaws and lake of sinus pneumatization..$^{11,12}$

\section{According to Ferreire et al.,2004, ${ }^{13}$ Zachariades} et al., 2006, ${ }^{14}$ mandibular fractures are the most common in maxillofacial region in pediatric patients. This priority of the mandibular fracture representing $75 \%-90 \%$ is probably due to bone is mobile and therefore has less bone support than the bones of the mid face.

There are several methods for management of mandibular fracture, one is conservative therapy with soft diet and/or minimal functional intermaxiallry fixation. The other methods applied in more complex fractures in both very young and the more adult patients, uses techniques standard to adult management, this includes open reduction and internal fixation. ${ }^{18}$

Mandibular fractures without great displacement with mild occlusal derangement are managed by close observation, a liquid to soft diet, analgesics and avoidance of physical activities. Displaced mandibular fractures need open reduction and internal fixation. ${ }^{15-18}$

Intermaxillary fixation using the primary teeth may be more difficult than in the adults, fewer number of the teeth, roots of the deciduous teeth may be resorbed, the surfaces are not retentive due to itching techniques and the crowns of the deciduous incisors and canines and partially erupted permanent teeth may be unfavorably shaped for the fixation of interdental wires and arch bars. ${ }^{19-21}$

Open reduction and internal fixation provide stable three-dimensional stability, promotes primary bone healing, shortens treatment time and eliminates the need for MMF. Decreased dependence on MMF improves post-operative respiratory care nutritional intake and oral hygiene mesures. ${ }^{12}$

In our study, males exceeded females in numbers with a male incidence of $77.8 \%$, this goes in accordance with Batainch, 1998 ${ }^{22}$ and Van Beek \& Merkx, 199923, who attributed this fact to the greater and more dangerous activities among boys.

In our study, the incidence of mandibular fractures is less common in children younger than 5 years and increases with age. This is in agreement with the findings of study achieved by Sejii \&Tokujo, $2002^{24}$, who found, the incidence of maxillofacial fractures in children increases. This may be due to the fact that children are more protected by their families and therefore they are less exposed to accidents or injuries likely to cause fractures in other age groups as the children grow to social environment changes they go to school, they participate in sports and do body contact activities that increase the risk of trauma. ${ }^{25}$

Sports and road traffic accidents were the main etiologic factor in our study in percent of $39 \%$ and $27.5 \%$ respectively, this was found to be parallel with findings of Benait et al.,2000 ${ }^{26}$, Posniek et al., 
$1993^{12}$, who found that the sports and road traffic accidents were the main etiologic factor of fracture of the mandible in the preschool children.

The most frequently affected sites in our current study were the symphsis and parasymphysis followed by body and angle of the mandible in the three groups and this was in agreement with Tanaka et al., $1993^{27}$, who reported higher incidence of symphysial fractures followed by parasymphysial, body and condylar fractures.

Following the recommendation of Styloganni et al.,1991 ${ }^{28}$, who determined that, the pediatric facial fractures should be reduced and immobilized as soon after trauma as the general condition improved because of fractures of the facial region unite very rapidly at this age.

Treatment of mandibular fractures using open reduction and internal fixation through an intraoral approach in our study provided the advantages of simultaneous visualization of the fracture line and occlusion relation. It also eliminated extra oral incision and the risk of scar formation and this was in agreement with studies reported by Schon et al., $2002^{29}$, Toma et al., 2003 30 .

The application of microplates in our study was done with minimal efforts due to its malleability so, it was easily adapted to the bone, there were no cases of palpability or postoperative paraesthesia and this was in agreement with (Hang \& Morgan,1995) ${ }^{31}$ the risk of potential damage to teeth roots and follicles in our study might be minimized with a careful technique of short monocortical screws especially in the case of upper border plates and as possible away from teeth buds and this is according to Davison et al., $2001{ }^{18}$ Nixon and Lowey,1990 ${ }^{32}$.

Miniplates used in this study provide greater stability with minimal inter fragmentary motion allowing rapid healing and this was in agreement with Monson et al., $\mathbf{1 9 8 5}^{33}$ as they determined that miniplates were designed to provide multipoint of bone fragment fixation there by preventing rotational migration of the fragments and providing interfragment stability and miniplating systems contribute to rapid bone healing.

Cases of group (1), treated by miniplates all are placed at the inferior border of the mandible to avoid injury of the developing teeth buds this was in agreement with studies achieved by Eppley, 2005 ${ }^{5}$, Martins et al., $2003^{34}$, as they reported that when using miniplates in mandibular fracture fixation in children should be placed at the inferior border of the mandible by directing the screws away from the developing teeth buds as this will help to prevent injury to the developing teeth buds which may result in failure of eruption of the permanent teeth.

In a study of 92 children with mandibular fractures Hard and Gottsauner, $1993^{35}$, found that no growth disturbances caused by miniplates or any surgical procedures for reduction and fixation on the treated side compared with the opposite side.

All cases of group (2) treated through open reduction and internal fixation using microplates achieved initial stability of fracture segments intraoperatively and all over the different follow up periods, this is approved that the mechanical properties of microplates were enough to produce stability in pediatric mandibular fracture and also, due to the strength of musculature of children is less than in adults and according to Davison et al.,2001 ${ }^{18}$ the pediatric mandible is fairly malleable, fracture tend to be less displaced and more growth expected, absolute compression of the fracture edges together is not necessary.

In group (3) using the copolymer PDLLA in fixation of pediatric mandibular fractures as these types of osteosynthesis recommended for children because of fast resorption and less risk of growth impairment for fast growing skeleton and this as the recommendation of Suuronen et al., 199935 who determined that these plate possess greater 
properties of biological degradation process is both predictable and safe.

Suuronen et al., $1999^{35}$ reported that biodegradable material mainly polymers and copolymers of polylactide and polyglycolide can be used safely in orthognathic and trauma surgery. So, Sanel et al., 2006, ${ }^{36}$ explained that, the biodegradable plates and screws may be applied in the infant mandible where the entire bone is composed of teeth and could be an alternative method and this resulted in excellent stability and healing of the fractures, and this was in agreement with the result of our study in group (3) with using of resorbable bone plates in pediatric mandibular fractures achieve proper healing and stability.

Biodegradable plates and screws are used increasingly in oral and maxillofacial practice, these plates have several advantages over conventional titanium plates including no need for a second intervention to remove the devices, no interference with imaging or radiotherapeutic techniques, no possible growth disturbances, no potential brain damage and no thermal sensitivity. ${ }^{35}$

In our study, primary wound healing was achieved uneventfully in 32 children and there was scarring in four children, this incidence of proper healing attributed to the application of the plates via an intraoral approach, where small intraoral incision limits the amount of disruption of the periosteum resulting in improved vascularity to the chance of postoperative complications.

Four cases of all patients of our study developed mild infection on the sixth post-operative day which were treated accurately with the same regimen of antibiotics and anti-inflammatories at the incision site and not need any intervention of incision and drainage, or plate removal, cases of infection of our study were recorded in the parasymphyseal regions as in this area the vestibule is more dependent and susceptible to pooling of food and secretions that may increase the chance of infection, this was in agreement with the studies achieved by Vallentino et al., $1994^{36}$ clinical evaluation revealed marked stability in all patients as none of the patients developed malunion or nonunion. There is no obvious occlusal derangement of all cases and only minor occlusal derangement in only two cases of group (3) corrected by placement of light guiding elastics according to Laugblin et al., 2007.37

Radiographical examination of the patients involved in our study showed perfectly aligned fracture segments and there were no bony resorption around the plates or screws. Healing at the fracture site was progressively noticed as the fracture lines were difficult to be detected after 3 months.

According to Chen \& Hollender, $1995{ }^{10}$, the more gray levels the more the contents of the calcified tissues. The analysis of radiographic results of our study showed significant and better healing of the fracture line in gray level value at the different follow up periods, also, there was significant increase in the mean value of the bone mineral density from one month to three months postoperatively.

In our study, all cases of the three groups there was no injury to the teeth germs in any of the treated children as discovered on the basis of the clinical and radiographical evaluation.

Panoramic radiograph with computerized radiograph level scales revealed stability of the reduced segments in all cases all over the follow up periods with significant bone gain at the fracture line at one, three, and six months, indicating that of proper fracture healing.

\section{CONCLUSION}

Monomandibular osteosynthesis using miniplates, microplates, and biodegradable plates precludes dependence on the maxillomandibular fixation, ensure respiratory care, nutritional intake in 
children provided adequate stability of the fracture segments in treatment of pediatric mandibular fracture, minimize the possibility of trauma to the teeth buds. In addition the biodegradable plates characterized by no need for removal of the plates later on.

\section{REFERENCES}

1. Aldegheri A, Blane JH: The pearl steel wire, a simplified appliance for maxillomandibular fixation. $\mathrm{Br} \mathrm{J}$ Oral Maxillofac Surg 37:117-118;1999.

2. Hang RH, Foss J: Maxillofacial injuries in the pediatric patient. Oral Surg Oral Med Oral Pathol Oral Radiol Endodon.90:126-134;2000.

3. Caldoron S, Wiss N, Garlik J: A technique for the treatment of mandibular body fracture in young children. Int J Oral Maxillofac Surg.18:83-84;1989.

4. Buijs GJ, Rander Houwen EB, Stegenga B: Mechanical strength and stiffness of the biodegradable sonic weld $\mathrm{Rx}$ osteofixation system. Int J Oral Maxillofac Surg.67(4):782$787 ; 2009$.

5. Eppley BL: The use of resorbable plates and screws in pediatric facial fractures. J Oral Maxillofac Surg.63:385$391 ; 2005$.

6. Halland AJ, Broome C, Steinberg A: Facial fractures in children. Pediatric Emerg Care. 17:157;2001.

7. Goldstein JA: The use of bioresorbable materials in cranio facial surgery. Clin Plast Surg.28:563;2001.

8. Ghali GE, Sinn DP, Tonti Pasawasin S: Management of non syndromic cranio synostosis: Atlas Oral Maxillofacial Surgery Clin North Am.1:10;2002.

9. Eppilling E, Maria R, Theissing F, Stadlinger B: An experimental in vivo analysis of the resorption to ultra sound activated pins (sonic weld) and standard biodegradables screws (Resorbx) in sheep. Br J Oral Maxillofac Surg.35:70;2007.

10. Chen S, Hollender L.: Digitizing of radiographs which affect bed scanner. Br Dent. 23:205;1995.

11. Stylogianni L, Arisenopoulos A, Patriciou A: Fracture of the facial skeleton in children: Br J Oral Maxillofac Surg.29:39;1991.
12. Posnick JC, Wells M, Pron GE: Pediatric facial fractures: evolving patterns of treatment. J Oral Maxillofac Surg.51:836;1993.

13. Ferreira P, Silva N, Silva A, Cardoso A, Radriguess J, Reis J, Amoranto J: Pediatric facial fractures. Characterizes of Portug uses population.Acto Med, Port.123-129;2004.

14. Zachairdes N, Mezitis M, Murouzis C, Papadokis P, Spanou A: Fractures of the mandibular condyle: a review of 466 cases literature review, reflections on treatment and proposals. J Cranio Maxillofac Surg. 421-432;2006.

15. Down KE, Boot DA, Gorman DF: Maxillofacial and associated injuries in severely traumatized patients implication of a regional survey. Int J Oral Maxillofac Surg.24:409-412;1995.

16. Kellman R: Repair of mandibular fractures via compression plating and more traditional techniques: A comparison of results. Laryngoscope 94:1560;1984.

17. Guo S, Dipietro LA: Factors affecting wound healing. J Dent Res.89:219-229;2010.

18. Davison PS, Clifton SM, Davison N, Hedrich M: Pediatric fracture mandible (free hand technique) Arch Facial Plast Surg.3:185-189;2001.

19. Torogenson DS, Mayer MH, Ellenbogen RG: Detection of titanium in human tissues after craniofacial surgery. Plast Reconstr Surg.99:976-979:1979.

20. Zimmermann CE, Trdulis MJ, Kaban LB,: Pediatric facial fractures: Recent advances in prevention, diagnosis and management. Int J Oral Maxillofac Surg.35:2-13;2006.

21. Rowe NL, Killey HC: Fractures of the mandible in children. Fractures of facial skeleton Edinburgh, London: E \& S Living Stone LTD,173-179;1968.

22. Bataineh $\mathrm{AB}$ : Etiology and incidence of maxillofacial fractures in the North of Jordan. Oral Surg Oral Med Oral Pathol Oral Radiol Endodon.86:31-35;1998.

23. Van Beek GJ, Merkx CA: Changes in pattern of fractures of maxillofacial skeleton. Int J Oral Maxillofac Surg.28:424$428 ; 1999$.

24. Seiji I, Tokuzo M: Pediatric maxillofacial fractures: their aetiological character and fracture patterns: J Cranio Maxillofac Surg.30:237-241;2002.

25. Zerfowsk M, Bremerich A: Facial trauma in children and adolescent. Cli Oral Investting.120:124;1998. 
26. Benoit R, Watts DD, Dwyer K: A source of suburban pediatric trauma. J Trauma.49;477-481;2000.

27. Tanaka N, Uchide N, Suzuki K: Maxillofacial fractures in children. J Cranio Oral Maxillofac Surg.29:39;1991.

28. Stylogianni L, Aresenopoules A, Patrikcou A: Fractures of facial skeleton in children. Br J Oral Maxillofac Surg. 29:39; 1991 .

29. Schon R, Gutwald R, Schramm A: Endoscopy assisted open treatment of condylar fractures of the mandible. Extra oral vs intraoral approach. Int J Oral Maxillofac Surg.31:237;2002.

30. Toma v, Mathog R, Toma R, Meleca R,: Transoral vs extraoral reduction of mandibular fractures: a comparison of complication rates and other factors. Otolaryngol Head Neck Surg,. 128;215;2003.

31. Haug RH, Morgan JP: A microplate and screw technique for intra oral open reduction of mandibular angle fractures. J Oral Maxillofac Surg..55:218-219;1995.
32. Nixon F, Lowey MN: Failed eruption of the permanent canine following open reduction of a mandibular fracture in a child. Br Dent J.168:204-205;1990.

33. Manson PN, Grawley WA, Yaremchuk MJ: Midfac fractures: advantages of immediate extended open reduction and bone grafting. Plast Reconst Surg.76:1-10;1985.

34. Martins C, Marianowski R, Potard G, Pondaven S, Jezequel J: Prognosis of mandibular fractures in pediatric population. Int Congress Series.1254:473-475;2003.

35. Suuronen R, Haers PE, Lindquist $\mathrm{C}$ : Update on biodegradable plates in maxillofacial surgery. J Facial Plast Surg.15:61-72;1992.

36. Valentino J, Lery FE, Morentette LJ: Intraoral monocortical miniplating of mandible fracture. Arch Otolaryngol of Head Neck Surg.120:605;1994.

37. Laugblin RM, Block MS, Wilk R: Resorbable plates for the fixation of mandibular fractures: A prospective study: J Oral Maxillofac Surg.65:89-96;2007. 